\title{
Sensory Evaluation of Pinked Sauvignon Blanc Wines
}

\author{
A.P. Nel, ${ }^{1 *}$ W.J. du Toit, ${ }^{2}$ F.P. van Jaarsveld ${ }^{3}$ \\ (1) Cape Peninsula University of Technology, Hexberg Road, Wellington Campus, Wellington 7655, Western Cape, South \\ Africa. \\ (2) Department of Viticulture and Oenology, Stellenbosch University, Private Bag X1, Matieland 7062, South Africa \\ (3) ARC Infruitec-Nietvoorbij, Stellenbosch, 7600, South Africa
}

Submitted for publication: September 2020

Accepted for publication: July 2021

Keywords: Pinking, sensory analysis, Sauvignon blanc

\begin{abstract}
Sensorial studies on pinked white wines have never been carried out. The aim of this study was to establish the probability of an aroma and taste difference in pinked Sauvignon blanc wines using a triangular test. The issue of at which point a wine consumer can perceived the wine as pink was analysed using a ranking experiment. The probability that a wine taster can detect oxidised and pink wines as a wine fault was also analysed. It was found that the panellists could not detect anomaly samples by taste and aroma alone, although some noticed an oxidised aroma on the nose. The pink detection point was established at $0.03 \mathrm{AU}$. This point can be used to refine the detection point and the assay used. It was established that more than $50 \%$ of the panellists could detect oxidised and pink wines as a wine fault. The study data can be used to either train panellists to detect pinking as a wine fault, or to establish a potential new category for pink Sauvignon blanc wines.
\end{abstract}

\section{INTRODUCTION}

Pinked wines are defined as white wines that show a pink colouration under certain winemaking conditions and were first described by Singleton and Esau in 1969. Many white cultivars are affected by the pinking phenomenon, including Albariño, Chardonnay, Chenin blanc, Crouchen, Doradillo, Garnatxa blanca (Grenache), Grüner Veltliner, Macabeo, Muscat Gordo Blanco, Pálava, Palomino, Parellada, Pinot Gris, Riesling, Sauvignon blanc, Semillon, Síria, Sultana, Thompson Seedless, White Riesling and Xarel-lo (Simpson, 1977a; Tobe, 1983; Jones, 1989; Lamuela-Raventós et al., 2001; Andrea-Silva et al., 2014; Nel et al., 2020). Simpson (1977a) describes pinking as a troublesome discolouration that develops after normal winemaking production. Sometimes the discolouration only develops after bottling and storage, when certain winemaking processes lead to an influx of oxygen (Simpson, 1977a; Simpson et al., 1982). The pink discolouration that takes place could be so slight that it cannot be noticed, or it could be confused with browning (Simpson, 1977b).

Anecdotal evidence suggests that the pinking of white wine does not influence the taste or the aroma of the wine (Simpson, 1980). Although extensive sensory research has been done on Rosé- and Blanc de noir-styled wines in terms of flavour, aroma, sweetness and colour (Amerine \& Ough, 1967; Ellis \& Kok, 1987; Huertas et al., 2003; Gamasa et al., 2009; Masson \& Schneider, 2009; Darici et al., 2014), little work has been conducted on pinking in white wines.
A wine taster uses his/her senses (sight, smell and taste) to assess a wine. The wine taster extracts a lot of information from the colour of a wine, including the age, maturity and possible defects of the wine (Wang \& Spence, 2019). It is for this reason that the colour of a wine is so important to a winemaker when judging the quality of a wine. Several aroma characteristics of the wine are assessed, like quality, the intensity of aroma and temporal attributes (i.e. the change in aroma over time, which influences both quality and intensity) (Jackson, 2009). These aroma attributes give clues to the wine taster of the finer nuances of the wine and what to expect when the wine is tasted. Two types of oral chemoreceptors are used when a wine is evaluated sensorially. The specialised receptors, which are situated in cavities of the taste buds, register the gustatory (taste) perception of sweet, sour, bitter, salt and umami (savoury). The free nerve endings generate the perception of astringency, dryness, burning, puckering and pain. The combination of the chemoreceptors in the mouth with the receptors in the nose produces the perception of flavour (Jackson, 2009). Pinking in white wines is related to oxidation (Singleton et al., 1979; Simpson, 1980; Du Toit et al., 2006). Some cultivars, such as Sauvignon blanc, are oxygen-sensitive (Day et al., 2015) and are more prone to pinking (Simpson, 1977a, 1977b; AndreaSilva et al., 2014). Some of the chemical components that are key to oxygen-sensitive cultivars are strongly modulated by exposure to oxygen, triggering a chain of chemical reactions

*Corresponding author: nelap@cput.ac.za

Acknowledgements: The authors would like to thank the Agricultural Research Council for the use of their laboratories, Winetech for funding the research, and Prof Martin Kidd for statistical analysis 
and consequently altering the wine composition. For this reason, it would be expected that a trained wine taster could pick up notes of oxidation in pinked wines.

In studies done by Simpson (1977a, 1977b), the minimum absorbency for a wine to be deemed as pink was established as 0.05 AU. In his pioneering study, Simpson found that, by adding hydrogen peroxide $\left(\mathrm{H}_{2} \mathrm{O}_{2}\right)$ and waiting for 24 hours, the wines with a high tendency to pink will have an absorbency of 0.05 units, and higher after the treated samples were subtracted from the absorbency of the control wine (Simpson, 1977a). Simpson's method was adopted by the wine industry worldwide and is still used today in all wine laboratories to test for pinking susceptibility. The norm is that, when white wine is tested and, after the addition of $\mathrm{H}_{2} \mathrm{O}_{2}$, the absorbency is more than 0.05 AU measured at 500 $\mathrm{nm}$, the wine is seen as susceptible to pinking.

The aim of this study was to ascertain if a pinked white wine influences the sensory attributes of the wine. One experiment was designed to test the hypothesis that a wine taster cannot differentiate between the aroma of a pinked wine and that of a control wine. A second experiment was designed to test the hypothesis that a wine taster cannot differentiate between the taste of a pinked wine versus that of a control wine. Experiments one and two were based on triangular tests. A third experiment tested the taster's ability to rank various pinked wines - from the control sample to a heavily pinked wine - to establish the absorbency unit (AU) at which wine is visually perceived as pink. A fourth experiment aimed to establish the wine taster's ability to identify an oxidised wine and a pinked wine. This study represents novel work, as it is the first known reported investigation on the influence of pinking on the taste and aroma of a wine.

\section{MATERIALS AND METHODS \\ Wines}

The Sauvignon blanc wines for the sensorial analysis came from the 2018 vintage. Wine A was obtained from the Constantia ward, Coastal region, Western Cape, South Africa. The wines B and C were obtained from a cellar in the Robertson Valley district, Breede River Valley region, Western Cape, South Africa. The wines were untreated (no PVPP added) and the wine was filtered. The wines were sampled directly from the tank early in the morning. Cleaned green wine bottles $(750 \mathrm{~mL})$ were filled with $\mathrm{CO}_{2}$ gas to prevent oxidation in the bottle before filling. The wines were immediately sealed with a cork after the bottles were filled. The ambient temperature was about $20^{\circ} \mathrm{C}$ and the wine was transported early in the morning to keep it at the ambient temperature. The wine was refrigerated at a constant $10^{\circ} \mathrm{C}$ in the lab.

\section{Testing for susceptibility to pinking}

According to the SASEV (2002) Methods of Analysis for Wine Laboratories, a $0.072 \%(\mathrm{w} / \mathrm{v}) \mathrm{H}_{2} \mathrm{O}_{2}$ solution $(1.2 \mathrm{~mL}$ of $30 \%(\mathrm{w} / \mathrm{v}) \mathrm{H}_{2} \mathrm{O}_{2}$ in a $500 \mathrm{~mL}$ volumetric flask with distilled water) was used. For each wine sample, 6 x $25 \mathrm{~mL}$ sample bottles were filled with wine, of which three were kept as the control samples and $1.00 \mathrm{~mL}$ of the $0.072 \%(\mathrm{w} / \mathrm{v}) \mathrm{H}_{2} \mathrm{O}_{2}$ solution was added to the other three treatment bottles. The sample bottles were mixed gently and left in a dark cabinet at $20^{\circ} \mathrm{C}$ for at least eight hours. After eight hours, the samples were measured on a spectrophotometer at $500 \mathrm{~nm}$, zeroed with the control sample ( $0 \mathrm{~mL}$ of $\mathrm{H}_{2} \mathrm{O}_{2}$ added) and, if the $\mathrm{AU}$ was above 0.05 , the wine was seen as susceptible to pinking. Every sample was done in triplicate.

\section{Sensory evaluation panel}

Sensorial evaluations were conducted in the Department of Viticulture and Oenology at Stellenbosch University (SU), Stellenbosch, Western Cape, South Africa. The members of the sensory panel were given non-monetary incentives for their participation. The panel consisted of 14 tasters (two men and 12 women, of which the youngest was 22 and the oldest 62 , with a mean age of 43 years) who were trained by the University's sensory laboratory and were used for all the sensorial experiments. These people were industry professionals and industry experts (Brand, 2019). Every tasting was done in duplicate. The tasting took place in white partitioned booths so that the panellists could not influence one another. The wine was passed to them through a sliding door in front of the panellists or was covered with white paper.

\section{Sensorial evaluations}

A series of experiments were designed to establish a) if there is a taste and aroma difference in pinked wines, b) at which point a pink discolouration can be perceived, and c) if a tasting panel can differentiate between an oxidised and a pink wine.

\section{Evaluating sensory differences between control and pink wines}

Sauvignon blanc wine (wine A) with a high pinking susceptibility $\left(\mathrm{AU}_{500}\right)$ was used for the triangular tests. The triangular tests formed part of the experiment designed to test the hypothesis that a wine taster cannot differentiate between the aroma and taste of a pinked wine and that of a control wine. $\mathrm{CO}_{2}$ gas was blown into the control wine before sealing the bottles to prevent oxidation, while the other half was naturally pinked without the addition of hydrogen peroxide $\left(\mathrm{H}_{2} \mathrm{O}_{2}\right)$. Natural pinking was induced by pouring the wine over in empty bottles to add oxygen to the wine to help with the natural pinking process. After the initial airing, $\mathrm{CO}_{2}$ gas was blown on top of the wine to minimise further oxygen contact until the wine pinked naturally after about three days. Control and test (pinked) wines were then presented to the trained panel.

A triangular test was conducted in black ISO/INAO wine-tasting glasses (International Organization for Standardization [ISO], 1977). Fifty millilitre wine samples (wine A) were served at an ambient temperature of $20^{\circ} \mathrm{C}$ in the tasting glasses and covered with a petri dish for $1 \mathrm{~h}$ before tasting. Fourteen panellists received two control wines and one pink wine, while 14 panellists received one control and two pink wines. After taking a break, the panels changed around and tasted the opposite wine combination. This process was done twice, as the panellists first had to point out the odd sample on aroma (experiment 1) and, after taking a break of one hour, had to come back and identify the 
odd sample on tasting (experiment 2). The replicates were done in triplicate.

\section{Ranking the point of pinking perception}

Sauvignon blanc wine (wine B), was used for the ranking experiment, which tested the taster's ability to rank various pinked wines - from the control sample to a heavily pinked wine - to establish the point at which a wine is perceived as pink. The wine $\left(\mathrm{AU}_{500} 0.034 \mathrm{~nm}\right)$ was then poured, under a blanket of $\mathrm{CO}_{2}$, into $6 \times 750 \mathrm{~mL}$ green glass bottles. Each bottle of wine was coloured artificially, with a Rosé wine $\left(\mathrm{AU}_{500} 0.210 \mathrm{~nm}\right)$ obtained from the same cellar in the Robertson valley, to obtain $0.01,0.02,0.03,0.04$ and 0.05 absorbency units (AU) at $500 \mathrm{~nm}$ using a VWR UV-1600 PC spectrophotometer (VWR UV-1600PC Spectrophotometer, Monitoring and Control Laboratories, South Africa). One bottle of the Sauvignon blanc wine, with no Rosé addition, was used as the control and one Rosé wine was used as the extremity for colour representation.

Clear ISO/INAO tasting glasses were used. Each sample set was randomised so that no panellists had the same sequence, and panellists had to rank the wine from the least to the most intense pink wine, also indicating at which minimum point they perceived the wine as pink (Fig. 1). The samples were evaluated in individual tasting booths. Data was collected at the Stellenbosch University Sensory Laboratory using paper ballots designed specifically by the laboratory (Addendum A).

\section{Distinguishing between oxidised and pinked wines as wine faults}

Sauvignon blanc wine (wine C) was used for the identification of pinking and oxidation as wine faults, forming part of the fourth experiment. Two bottles of the wine were artificially pinked with a Rosé wine (see Rank the point of pinking perception) to correlate with $0.02 \mathrm{AU}$ and $0.03 \mathrm{AU}$. Two bottles of the wine were hyper-oxidised by blowing $\mathrm{O}_{2}$ through the wine until a brown colour was obtained $\left(\mathrm{AU}_{420}\right.$ $-0.171)$.

Clear ISO/INAO tasting glasses were used. Each sample set was randomised so that no panellist had the same sequence and every glass was covered with white paper so that panellist could not see the colour of the wine (Fig. 2) before the evaluation started. The samples were evaluated in individual tasting booths and only one sample could be uncovered at a time. Data was collected using paper ballots specifically designed by the Sensory Laboratory of Stellenbosch University (Addendum B). There were two samples of control wines (K1 and K2), two samples of oxidised wine (Ox1 and $\mathrm{Ox} 2)$ and two pink wine samples (P0.02 and P0.03). The panellists were asked if they could detect a colour difference in the wine and, if so, what they thought the reason was for the colour difference. When a panellist could not distinguish between an oxidised and a pink wine, they indicated it as oxid/pink.

\section{Statistics}

Roessler tables for the minimum number of correct judgements to establish significance at various probability levels for a triangle test (one-tailed, $p=1 / 3$ ) were used (Roessler et al., 1978; Stone \& Sidel, 1993). Statistical evaluation for the triangular test dictates that 15 of the 28 respondents had to correctly identify the sample for $\mathrm{p}=0.05$ to be of significance (Roessler et al., 1978). For the other two sensorial evaluations, cross-tabulation was used to compare the judged classifications with the true classifications of the

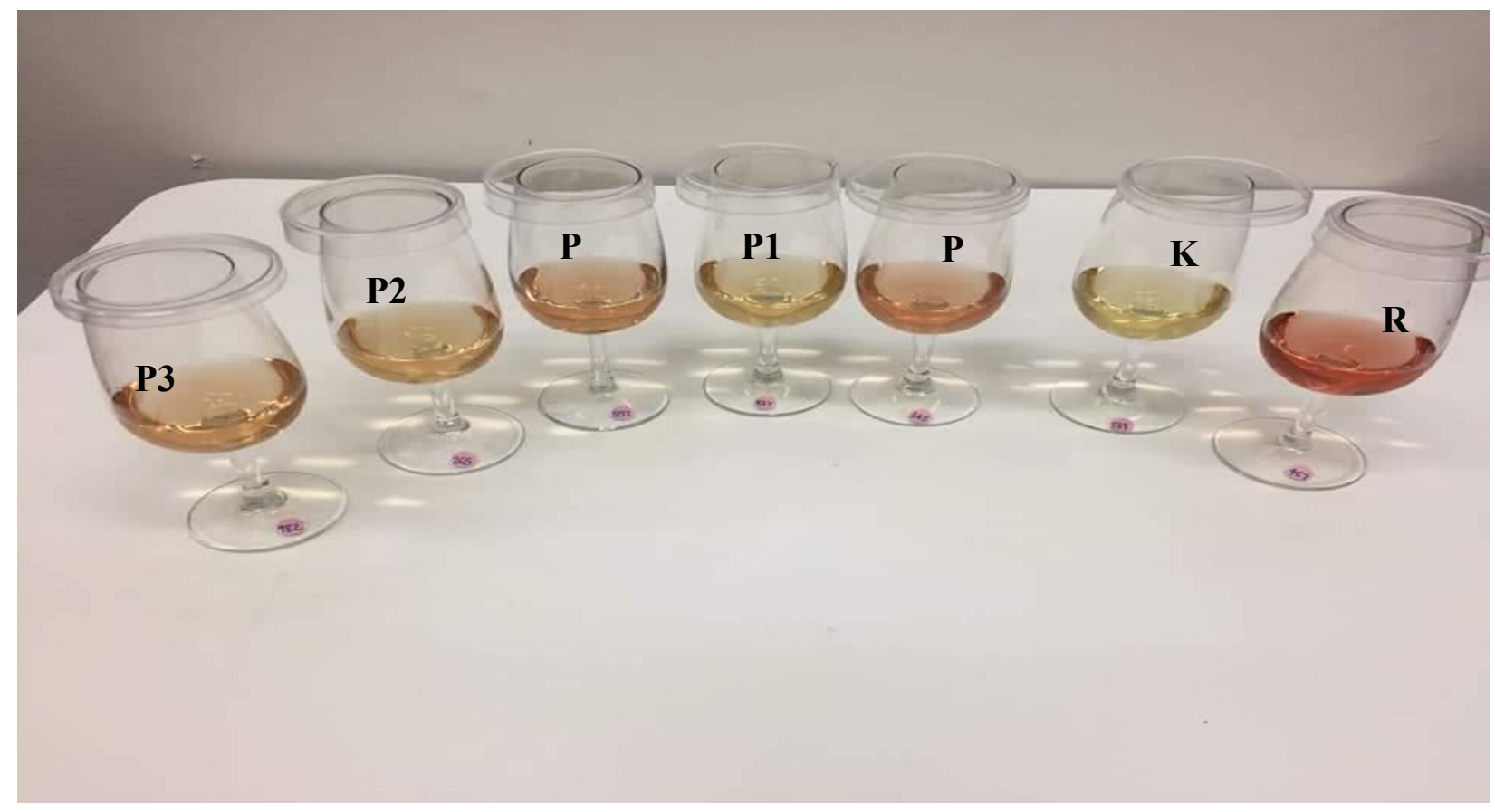

FIGURE 1

Wines corresponding to $0.01(\mathrm{P} 1), 0.02(\mathrm{P} 2), 0.03(\mathrm{P} 3), 0.04(\mathrm{P} 4)$ and $0.05(\mathrm{P} 5)$ AU with a control (K) wine and a Rosé (R) wine 


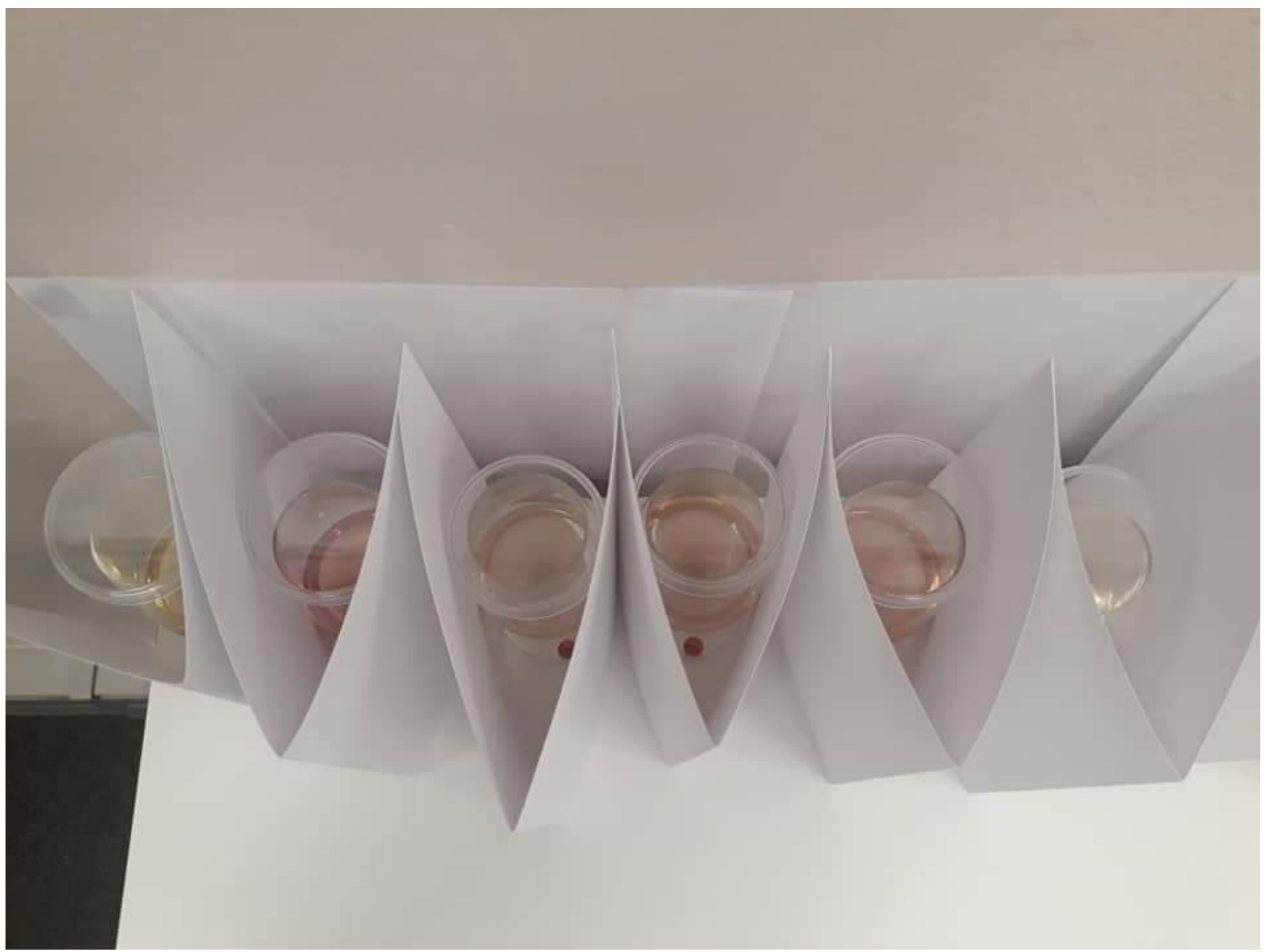

FIGURE 2

Example of sample preparation for distinguishing between oxidised and pinked wines as wine faults. The control, oxidised and pink wines were covered with a piece of white paper so that the tasters were not influenced. The samples were evaluated in individual tasting booths and only one sample could be uncovered at a time.

wines. Tests for an association between judged and actual classification were done using Chi-square and generalised Fisher exact tests with Statistika 13.0 (TIBCO Software Inc., USA). Adjustments for repeated responses from the same judge were done using Rao and Scott $(1981,1987)$ adjustment.

\section{RESULTS AND DISCUSSION \\ Evaluating sensory differences between control and pink wines}

Anecdotal evidence (Simpson, 1980) claims that, when white wines turn pink, it does not influence the taste and aroma of the wine. As this was never tested before, a sensory evaluation was performed to challenge the anecdotal evidence of Simpson (1980). As specified by the Roessler tables, 12 of 14 panellists is the minimum number to agree for a triangular tasting to have a significant difference of $\mathrm{p}=0.05$ (Roessler et al., 1978). Three Sauvignon blanc samples (two control and one pink, and one control and two pink) were presented to two groups of 14 professional panellists in triplicate in dark glasses. The panellists were asked to identify the anomalous sample from the three samples on aroma alone. In Table 1, it can be seen that, on average, only six, 7.5 and eight of the panellists respectively could correctly identify the anomalous sample. Two conclusions can be drawn, i.e. that it is not possible for panellists to correctly identify the pinked wine from a normal wine based on aroma, or that the panellists learned by experience. Some panellists who correctly identified the anomalous sample commented on their ballot papers that there was a slight indication of oxidation on the nose, which led to the conclusion that the panellists could identify pink wine on the aroma. This could be explained by the ingress of oxygen during the natural pinking process. This oxidation process can result in a change in aroma (Singleton et al., 1980; Simpson et al., 1982, 1983; Razmkhab et al., 2002; Du Toit et al., 2006, Coetzee et al., 2016).

The panellists were then asked to identify the anomalous sample between regular samples on taste alone (experiment 2). In Table 2, on average, only eight, 6.5 and six of the panellists respectively could correctly identify the anomalous sample. Therefore, it was not possible for the panellists to correctly identify this pinked wine from a normal wine based on taste. This means that the panellists could not significantly identify a pinked wine on taste alone. According to Franco-Luesma et al. (2019), wine tasters can hesitate when tasting a wine. 
TABLE 1

Results from the triangular test depicting the number of assessors who identified the different samples correctly on aroma.

\begin{tabular}{|c|c|c|c|c|c|c|}
\hline \multicolumn{7}{|c|}{ Aroma } \\
\hline & \multicolumn{2}{|c|}{ Rep. $1, n=28$} & \multicolumn{2}{|c|}{ Rep. $2, \mathrm{n}=28$} & \multicolumn{2}{|c|}{ Rep. 3, $n=28$} \\
\hline & Decisive & Non-decisive & Decisive & Non-decisive & Decisive & Non-decisive \\
\hline 2K1P & 4 & 9 & 6 & 7 & 8 & 5 \\
\hline $1 K 2 P$ & 8 & 7 & 9 & 6 & 8 & 7 \\
\hline Average & 6 & 8 & 7.5 & 6.5 & 8 & 6 \\
\hline
\end{tabular}

$\mathrm{K}=$ Control wine; $\mathrm{P}=$ pinked wine; decisive = panel members correctly identified the correct sample; non-decisive = panel members who could not correctly identify the correct sample; $n=$ the total number of samples; Rep. 1 to $3=$ Sauvignon blanc repeats

TABLE 2

Results from the triangular test depicting the number of assessors who correctly identified, on taste, the anomalous sample.

\begin{tabular}{lcccccc}
\hline \multicolumn{7}{c}{ Taste } \\
\hline & \multicolumn{2}{c}{ Rep. 1, $\mathbf{n}=\mathbf{2 8}$} & \multicolumn{2}{c}{ Rep. 2, $\mathbf{n}=\mathbf{2 8}$} & \multicolumn{2}{c}{ Rep. 3, $\mathbf{n}=\mathbf{2 8}$} \\
2K1P & Decisive & Non-decisive & Decisive & Non-decisive & Decisive & Non-decisive \\
1K2P & 6 & 7 & 5 & 8 & 5 & 8 \\
Average & 10 & 5 & 8 & 7 & 7 & 8 \\
\hline & $\mathbf{8}$ & $\mathbf{6}$ & $\mathbf{6 . 5}$ & $\mathbf{7 . 5}$ & $\mathbf{6}$ & $\mathbf{8}$
\end{tabular}

$\mathrm{K}=$ Control wine; $\mathrm{P}=$ pinked wine; Decisive = panel members correctly identified the correct sample; non-decisive = panel members who could not correctly identify the correct sample; $\mathrm{n}=$ the total number of samples; Rep. 1 to $3=$ Sauvignon blanc repeats

This hesitation can suggest that the taster does not pick up the oxidation notes and perceives the wine just as it is, but the panellists might pick up the oxidation notes if they are familiar with these. In this study, it became clear that the panellists hesitated in favour of the non-oxidised notes. The pinking of white wine is preceded by the ingress of oxygen during the winemaking process or at bottling (Singleton et al., 1979). The normal aroma of oxidation is associated with aldehydes and ketones (Waterhouse \& Laurie, 2006; Coetzee et al., 2016). Therefore, two possible explanations are possible. First, the perception of an oxidation aroma could explain the correct identification by the panellist on aroma alone and, secondly, that some familiarity could help the panellist to better identify a wine.

In conclusion, even though the pink wines in these experiments were briefly exposed to air to initiate pinking, in contrast to the control wine, which was kept under a $\mathrm{CO}_{2}$ blanket, no significant differences could be picked up by the panellists in the taste of the wines, but there was a probability that the taster could identify a difference in the aroma. This may prove the anecdotal evidence that there is no negative effect on the taste of pinked wines, but that some panellists may pick up aroma differences (Simpson, 1977a).

\section{Ranking the point of pinking perception}

During the ranking exercise, the panellists could arrange the samples in order from the lightest wine to the darkest wine. The panellists had to record the sample for which they observed a definite colour change. At an AU of 0.01, the wine had a slightly darker hue, but the panellists indicated that it was still within an acceptable range. It was only from $0.02 \mathrm{AU}$ and higher that the panellists could start to distinguish between a pinkish wine and a control wine. At $0.03 \mathrm{AU}, 53 \%$ of the panellists reported the colour change as pink. The value separating the indication point at which the panellists noticed the pink colour change was $0.03 \mathrm{AU}$ (Fig. 3). Using this data, it would be possible to fine tune the pinking assay to include $0.03 \mathrm{AU}$ as the cut-off absorbency for pinking susceptibility.

Versari et al. (2008) state that it is difficult to correlate the relationship between wine colour and its chemical composition. Hernández et al. (2011) also found that there is a general lack of agreement about absorbance measurements and visual colour assessment. This explains why the panellists only start noticing the pink colour change at 0.03 AU.

\section{Distinguishing between oxidised and pinked wines as wine faults}

The comments made by some of the panellists in the section on Evaluating sensory differences between control and pink wines made it clear that the aromas of the pink wine resembled oxidation. The hypothesis that a sensory panel can distinguish pinking from oxidised wines was tested in this experiment. A range of wines, which included control, oxidised and pinked wines, were given to a panel of trained tasters in a completely randomised order. They were asked to visually identify a wine fault, if any, in the wines given to them. 


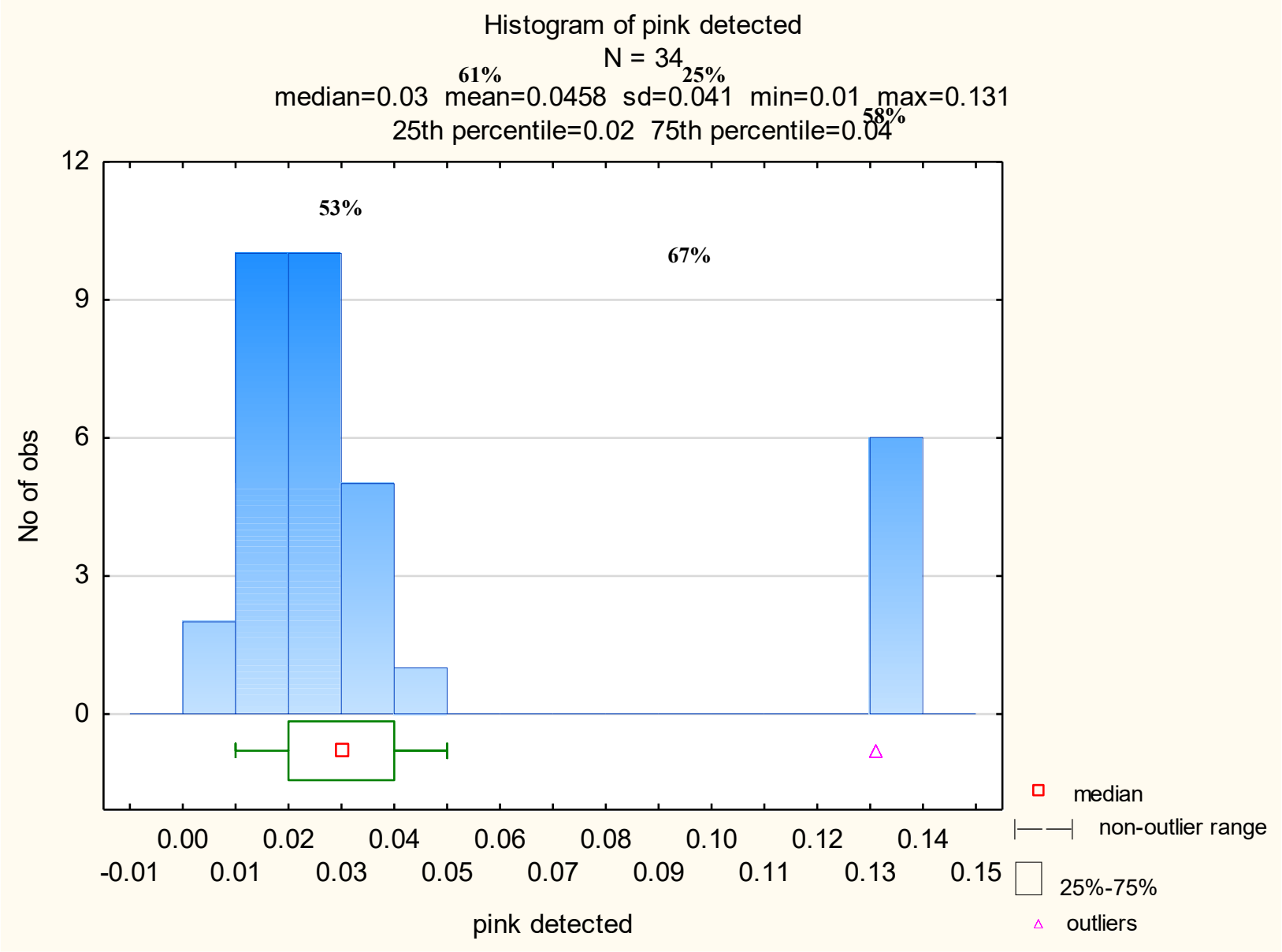

FIGURE 3

A histogram depicting the median point at which the observers noticed a differentiation in the colour of the wine samples. The bar on the far right is the Rosé wine.

In Fig. 4A, the panellists' ability to correctly identify the control wine (untreated but filtered 2018 Sauvignon blanc) was a significant $52 \%$, while $15 \%$ and $22 \%$ respectively incorrectly classified the oxidised and pinked wines as the control samples. Eleven percent of the panellists indicated a colour defect but were uncertain if the sample was pink or oxidised. They rated the colour defect as oxidised or pink, i.e. category oxid/pink in Fig. 4A. The ability of the panellists' to classify pink samples is indicated in Fig. 4B. A significant $67 \%$ of the panellists could correctly identify a pinked wine by default, while $8 \%$ thought that the control and oxidised samples were pink as well. Seventeen percent of the panellists indicated a colour defect, but were uncertain if the sample was pink or oxidised and rated the colour defect as oxidised or pink, i.e. category oxid/pink in Fig. 4B. The panellists had difficulty in identifying oxidised samples. Fifty-three percent correctly identified the oxidised samples, but $29 \%$ thought that the control wine was oxidised as well, while only $7 \%$ thought that the pinked wine was oxidised (Fig. 4C). Eleven percent of the panellists indicated a colour defect, but were uncertain if the sample was pink or oxidised and rated the colour defect as oxidised or pink, i.e. category oxid/pink in Fig. 4C.
Even though the majority of panellists could correctly distinguish between the wine samples, there was still a high percentage of panellists who could not do this successfully. There could be various reasons for this, for instance the background of the panellists (Grohmann et al., 2018), how they are trained by the personnel of the sensory laboratory, whether a white or red wine is being tasted (Gawel \& Godden, 2008), their understanding of wine and winemaking, and their experience in identifying wine faults. Wang and Prešern (2019) suggest that training in blind tasting can improve the tasters' accuracy. Franco-Luesma et al. (2016) also suggest that the perception threshold differs between tasters and that some tasters are more sensitive to oxidation aromas than others.

\section{CONCLUSION}

There is no literature that reports scientific evidence that pinking affects the flavour of wine, making this study the first scientific approach to the sensory influence of pinking. Anecdotal evidence suggests that pinking does not affect the flavour of a wine; however, a trained panel in this study could differentiate differences in aroma but not in taste. The number of panel members who could identify pinked wines based on 


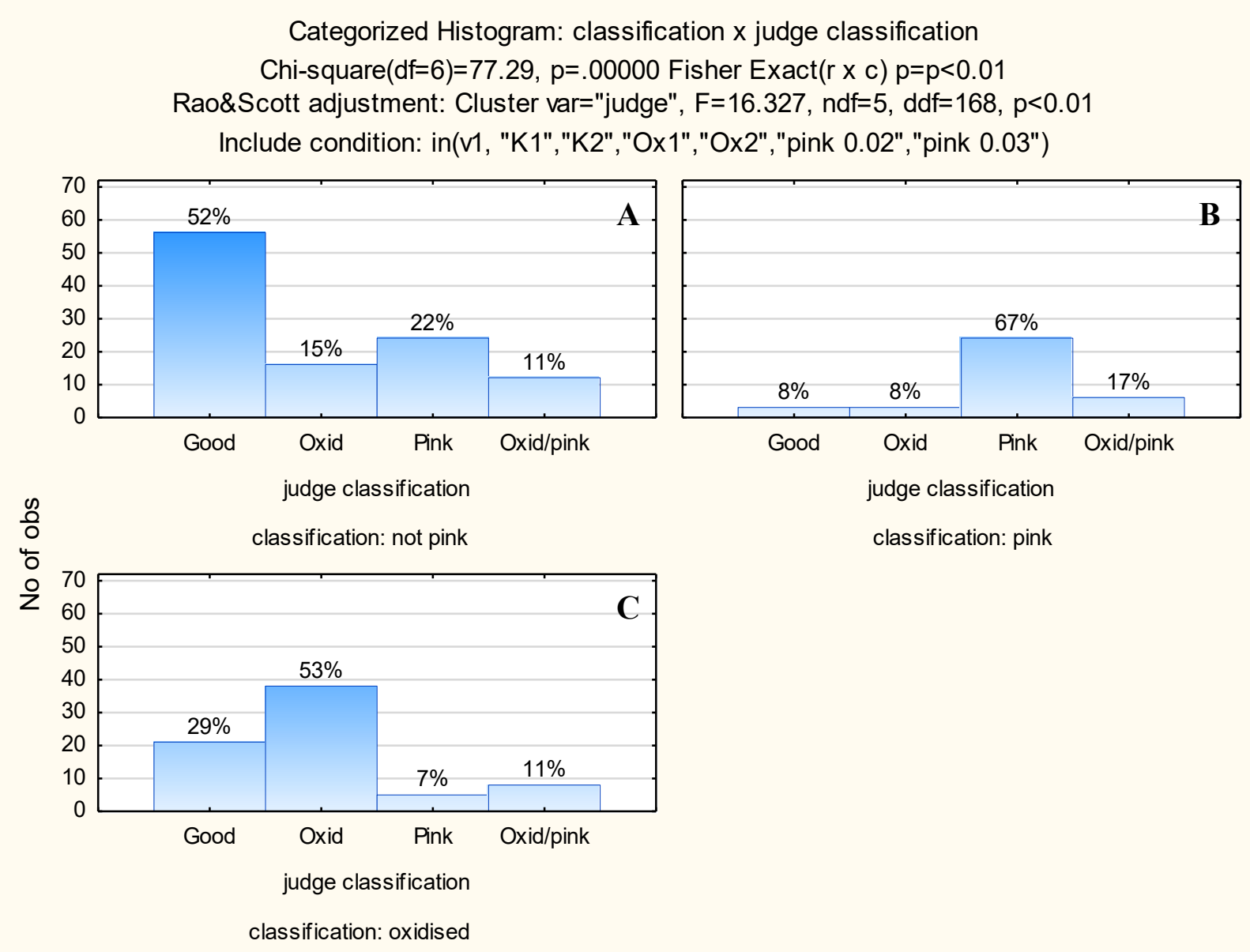

FIGURE 4

Categorised histogram depicting the classification of the wine against the panellist classification. K1 - control wine (Good) 1; $\mathrm{K} 2$ - control wine 2; Ox 1 - oxidised wine 1; Ox2 - oxidised wine 2; pink 0.02 - pink wine $1 \&$ pink 0.03 - pink wine 2; Oxid/ pink - uncertainty of panellists whether a wine was oxidised or pink. A - the judges' classification against the control samples

(Good); B - the judges' classification against the pink samples; $\mathrm{C}$ - the judges' classification against the oxidised samples

aroma, however, was only marginally (based on the Roessler scale) more than the non-decisive tasters, indicating that the wine would pass the consumers' lips without a second thought on the sensory and colour abnormality. A slight pink tint is not considered a fault by many international wine evaluators, although the South African Wine and Spirit Board considers pinking in white wines a wine fault. The point at which the pink discolouration or hue could be observed visually by the trained panel was at $0.03 \mathrm{AU}$, which is lower than the 0.05 AU specified by the assay for pinking potential. Therefore, instead of using $0.05 \mathrm{AU}$ in the assay, as prescribed by the South African Wine Laboratories Association (SAWLA), 0.03 can be used to detect earlier pinking susceptibility in wine. This study showed that panellists have the ability to distinguish between control, pinked and oxidised wines, which are results that would be useful in the future so that researchers, sensory panels and judges of wine competitions could be trained in distinguishing oxidised from pinked wines as wine faults.

\section{LITERATURE CITED}

Amerine, M.A. \& Ough, C.C., 1967. Sweetness preference in Rosé wines. Am. J. Enol. Vitic. 18(3), 121-125.

Andrea-Silva, J., Cosme, F., Ribeiro, L.F., Moreira, A.S.P., Malheiro, A.C., Coimbra, M.A., Domingues, M.R.M. \& Nunes, F.M., 2014. Origin of the pinking phenomenon of white wines. J. Agric. Food Chem. 62, 5651-5659.

Brand, J., 2019. Rapid sensory profiling methods for wine-workflow optimisation for research and industry applications. Thesis, Stellenbosch University, Private Bag X1, 7602 Matieland (Stellenbosch), South Africa.

Coetzee, C., Van Wyngaard, E., Šuklje, K., Ferreira, A.C.S. \& Du Toit, W.J., 2016. Chemical and sensory study on the evolution of aromatic and nonaromatic compounds during the progressive oxidative storage of a Sauvignon blanc wine. J. Agric. Food Chem. 64(42), 7979-7993.

Darici, M., Cabaroglu, T, Ferreira, V. \& Lopez, R., 2014. Chemical and sensory characterisation of the aroma of Çalkarası rosé wine. Austr. J. Grape Wine Res. 20, 340-346.

Day, M.P., Schmidt, S.A., Smith, P.A. \& Wilkes, E.N., 2015. Use and impact of oxygen during winemaking. Austr. J. Grape Wine Res. 21, 693-704.

Du Toit, W.J., Marais, J., Pretorius, I.S. \& Du Toit, M., 2006. Oxygen in must and wine: A review. S. Afr. J. Enol. Vitic. 27(1), 76-94. 
Ellis, L.P. \& Kok, C., 1987. Colour changes in Blanc de noir wines during ageing at different temperatures and its colour preference limits. S. Afr. J. Enol. Vitic. 18(1), 16-22.

Franco-Luesma, E.E., Honoré-Chedozeau, C., Ballester, J. \& Valentin, D., 2019. Oxidation in wine: Does expertise influence the perception? LWT Food Sci. Tech. 116, 108511.

Gamasa, C.S., Hernández, B., De Santiago, J.V., Alberdi, C., Alfonso, S. \& Diñeiro, J.M., 2009. Measurement of the colour of white and rosé wines in visual tasting conditions. Eur. Food Res. Technol. 229, 263-276.

Gawel, R. \& Godden, P.W., 2008. Evaluation of the consistency of wine quality assessments from expert wine tasters. Austr. J. Grape Wine Res. 14, $1-8$.

Grohmann, B., Peña, C. \& Joy, A., 2018. Wine quality and sensory assessments: Do distinct local groups of wine experts differ? J. Wine Res. 29(4), 278-289.

Hernández, B., Sáenz, C., Alberdi, C., Alfonso, S. \& Diñeiro, J.M., 2011 Colour evolution of Rosé wines after bottling. S. Afr. J. Enol. Vitic. 32(1), 42-50.

Huertas, R., Yebra, A., Pérez, M.M., Melgosa, M. \& Negueruela, A.I., 2003. Color variability for a wine sample poured into a standard glass wine sampler. Color Res. Appl. 28(6), 473-479.

International Organization for Standardization, 1977. ISO 3591:1977. Sensory analysis - Apparatus - Wine-tasting glass. https://www.iso.org/ standard/9002.html

Jackson, R.S., 2009 ( $2^{\text {nd }}$ ed). Wine tasting: A professional handbook. Elsevier, San Diego, CA.

Jones, T., 1989. Pinking of white table wines: Further studies. thesis, University of California, Davis, CA, USA

Lamuela-Raventós, R.M., Huix-Blanquera, M. \& Waterhouse, A.L., 2001 Treatments for pinking alteration in white wines. Am. J. Enol. Vitic. 52(2), 156-158.

Masson, G. \& Schneider, R., 2009. Key compounds of Provence Rosé wine flavor. Am. J. Enol. Vitic. 60(1), 116-122.

Nel, A.P., Du Toit, W.J. \& Van Jaarsveld, F.P., 2020. Pinking of white wines - A review. S. Afr. J. Enol. Vitic. 41(2), 151-157.

Rao, J.N.K. \& Scott, A., 1981. The analysis of categorical data from complex sample surveys: Chi-squared tests for goodness of fit and independence in two-way tables. J. Am. Stat. Assoc. 76, 221-230.

Rao, J.N.K. \& Scott, A.J., 1987. On simple adjustments to Chi-square tests with sample survey data. Ann Stat. 15(1), 385-397.
Razmkhab, S., Lopez-Toledano, A., Ortega, J.M., Mayen, M., Merida, J. \& Medina, M., 2002. Adsorption of phenolic compounds and browning products in white wines by yeasts and their cell walls. J. Agric. Food Chem. 50(25), 7432-7437.

Roessler, E.B., Pangborn, R.M., Sidel, J.L. \& Stone, H., 1978. Expanded statistical tables for estimating significance in paired-preference, paireddifference, duo-trio and triangle tests. J. Food Sci. 43(3), 940-947.

Simpson, R.F., 1977a. Oxidative pinking in white wines. Vitis 16, 286-294 Simpson, R.F., 1977b. Pinking in Australian white table wines. Austr. Wine Brew. Spirit Rev. November, 56-58.

Simpson, R.F., 1980. Some aspects of oxidative pinking of white wines Austr. Grapegrower Winemaker 204(12), 12-14

Simpson, R.F., Bennett, S.B. \& Miller, G.C., 1983. Oxidative pinking of white wines: A note on the influence of sulphur dioxide and ascorbic acid. Food Tech. Austr. 35(1), 34-36

Simpson, R.F., Miller, G.C. and Orr, G.L., 1982. Oxidative pinking of white wines: Recent observations. Food Tech. Austr. 34 (1): 44 - 47.

Singleton, V.L. \& Esau, P., 1969. Phenolic substances in grapes and wine and their significance. Adv. Food Res. Suppl. 1, 1-282.

Singleton, V.L., Trousdale, E. \& Zaya, J., 1979. Oxidation of wines I. Young white wines periodically exposed to air. Am. J. Enol. Vitic. 30(1), 49-54.

Singleton, V.L., Zaya, J. \& Trousdale, E., 1980. White table wine quality and polyphenol composition as affected by must $\mathrm{SO}_{2}$ content and pomace contact time. Am. J. Enol. Vitic. 31(1), 14-20.

Stone, H. \& Sidel, J., 1993. Sensory evaluation practices. Academic Press, Orlando, FL.

SASEV, 2002. Methods of analysis for wine laboratories. South African Wine Laboratory Association, Stellenbosch, South Africa

Tobe, S.J., 1983. Pinking in table wines from white grapes. Thesis, University of California, Davis.

Versari, A., Boulton, R.B. \& Parpinello, G.P., 2008. A comparison of analytical methods for measuring the color components of red wines. Food Chem. 106, 397-402.

Wang, Q.J. \& Prešern, D., 2019. Does blind tasting work? Investigating the impact of training on blind tasting accuracy and wine preference. J. Wine Econ. 13(4), 384-393.

Wang, Q.J. \& Spence, C., 2019. Drinking through rosé-coloured glasses: Influence of wine colour on the perception of aroma and flavour in wine experts and novices. Food Res. Int. 126, 1-11.

Waterhouse, A.L. \& Laurie, V.F., 2006. Oxidation of wine phenolics: A critical evaluation and hypotheses. Am. J. Enol. Vitic. 57(3), 306-313. 


\section{ADDENDUM A}

Flight

Judge name:

Date

Please rank the samples from the lightest colour to the darkest colour

Which sample is the first sample in the series that looks pink?

\section{Comments:}

The numbers in the first set of blocks are just an example of the randomised numbers that were allocated to the wine samples. Each panellist had his/her own set of randomised numbers. All the sample sets were also randomised so that no one panellist received the same numbers and sequence.

\section{ADDENDUM B}

Flight

Judge name.

Date

Please evaluate the samples one at a time. Take away the white carton of one sample at a time, immediately cover the sample again before assessing the next sample. Only one sample must be visible at a time.

Answer the following questions for all the samples.

\begin{tabular}{|l|l|l|l|l|}
\hline $\begin{array}{l}\text { Sample } \\
\text { code }\end{array}$ & Does the sample have a colour defect? & Yes & No & If yes, what was the colour defect? \\
\hline 508 & & & & \\
\hline 600 & & & & \\
\hline 754 & & & & \\
\hline 645 & & & & \\
\hline 671 & & & & \\
\hline 594 & & & & \\
\hline
\end{tabular}

The numbers in the first column (Sample code) are just an example of the randomised numbers that were allocated to the wine samples. Each panellist had his/her own set of randomised numbers. All the sample sets were also randomised so that no one panellist received the same number and sequence. 